\title{
Stop codon-mediated suppression of splicing is a novel nuclear scanning mechanism not affected by elements of protein synthesis and NMD
}

\author{
CHAIM WACHTEL, ${ }^{1}$ BINGHUI LI, ${ }^{1,3}$ JOSEPH SPERLING, ${ }^{2}$ and RUTH SPERLING ${ }^{1}$ \\ ${ }^{1}$ The Hebrew University of Jerusalem, Jerusalem 91904, Israel \\ ${ }^{2}$ The Weizmann Institute of Science, Rehovot 76100, Israel
}

\begin{abstract}
The pre-mRNA splicing machine must frequently discriminate between normal and many potential 5' splice sites that match the consensus sequence but remain latent. Suppression of splicing (SOS) at such latent $5^{\prime}$ splice sites is required for the maintenance of an open reading frame, and to ensure that only RNAs that encode for functional proteins will be formed. In this study we show that SOS is a novel mechanism distinct from the known RNA surveillance mechanisms. First, SOS is distinct from nonsensemediated mRNA decay (NMD) because it is not dependent on translation and is not affected by RNAi-mediated down-regulation of hUpf1 and hUpf2-two key components of the NMD pathway. Second, SOS is distinct from nonsense-associated alternative splicing (NAS), because a mutant of hUpf1, which was shown to abrogate NAS, does not activate latent splicing. Elucidating the mechanism of SOS is pertinent to human disease in view of the large number of human genes that harbor latent splice sites.
\end{abstract}

Keywords: ${ }^{\prime}$ ' splice site selection; latent splicing; nonsense-mediated mRNA decay (NMD); pre-mRNA splicing; RNA surveillance; stop codons

\section{INTRODUCTION}

Splicing of pre-mRNA requires the recognition of conserved pre-mRNA cis elements by several trans factors, such as spliceosomal U snRNPs and protein splicing factors, which assemble together to form the spliceosome (Burge et al. 1999). The cis elements are conserved sequences at the $5^{\prime}$ - and 3 '-ends of the introns, a branch site, a polypyrimidine tract, and exonic and intronic enhancer and silencer sequences. An important element affecting the accuracy and efficiency of the splicing reaction involves base pairing interactions between spliceosomal $U$ snRNAs and the premRNA consensus sequences. The $5^{\prime}$ splice site consensus sequence in the mammalian $\mathrm{U} 2$ spliceosome is AG/ GTRAGT (where R denotes purine and "/" denotes the splice junction) (Nilsen 1998; Staley and Guthrie 1998; Burge et al. 1999; Brow 2002). However, this site is not

Reprint requests to: Ruth Sperling, Department of Genetics, The Hebrew University of Jerusalem, Jerusalem 91904, Israel; e-mail: sperling@vms.huji.ac.il; fax: 97226586975.

${ }^{3}$ Present address: Cancer Research Institute, $1044 \mathrm{~W}$. Walnut Street, Indiana University Medical Center, Indianapolis, IN 46202-5225, USA.

Article published online ahead of print. Article and publication date are at http://www.rnajournal.org/cgi/doi/10.1261/rna.7480804. unique, as $5^{\prime}$ splice site consensus sequences that are not used for splicing are highly abundant (Miriami et al. 2002). The mechanism used to discriminate the authentic $5^{\prime}$ splice sites from the unused ones, termed herein latent $5^{\prime}$ splice sites, is not yet understood. An example of a latent $5^{\prime}$ splice site was previously found in an internal intron of the $C A D$ gene (Miriami et al. 1994). The sequence upstream of that latent site contained stop codons in the reading frame of the upstream exon. We proposed that splicing at this latent site is suppressed so that the formation of premature translation termination codon (PTC)-bearing mRNA is avoided.

PTC-bearing mRNAs are toxic to cells, and RNA surveillance mechanisms are required to eliminate such defective messages (Li and Wilkinson 1998; Culbertson 1999; Frischmeyer and Dietz 1999; Hentze and Kulozik 1999; Maquat 2002). A well studied pathway of RNA surveillance is the nonsense-mediated mRNA decay (NMD) pathway, whereby the abundance of the aberrant mRNAs is reduced to $5 \%-30 \%$ of the normal mRNA level (Jacobson and Peltz 1996; Li and Wilkinson 1998; Culbertson 1999; Frischmeyer and Dietz 1999; Hentze and Kulozik 1999; Hilleren and Parker 1999; Maquat 2002). In humans, an important group of proteins involved in NMD are the hUpf proteins: hUpf1, hUpf2, and hUpf3 (Sun et al. 1998; Lykke-Andersen 
et al. 2000, 2001; Mendell et al. 2000 2002; Gehring et al. 2003), which together provide substrate specificity for the recruitment of mRNA into the NMD pathway. Current models of NMD imply a "pioneer round of translation" of newly made RNA (Ishigaki et al. 2001). A protein complex that marks the exon-exon junction (EJC) of the spliced mRNA was proposed to provide a signal for NMD (Le Hir et al. 2001). In normal mRNAs the EJC is removed by the ribosome in the "pioneer round of translation." However, when the ribosome reaches a PTC while a downstream EJC is still associated with the mRNA, several proteins are recruited to the mRNA and trigger degradation by NMD (Maquat 2002). Although the cellular location of NMD is not yet resolved, and both nuclear and cytoplasmic models have been proposed, it is well established that NMD requires a round of translation (Maquat 2002).

Another pathway of eliminating PTC-bearing mRNAs is by nonsense-associated altered splicing (NAS) (Hentze and Kulozik 1999). Examples of exon skipping associated with PTCs are found in human genetic diseases (for review, see Maquat 1995), though several cases of exon skipping were attributed to the effect of PTCs on splicing control elements (Valentine 1998; Caputi et al. 2002; Cartegni et al. 2002). Other cases of NAS include intron retention (Aoufouchi et al. 1996; Gersappe and Pintel 1999), nuclear pre-mRNA accumulation (Mühlemann et al. 2001), and an altered splicing pathway (Mendell et al. 2002; Wang et al. 2002a). The mechanism of NAS is not yet known. Nonetheless, protein synthesis has been proposed to be involved in the NAS occurring in the T-cell receptor- $\beta$ mRNA (Wang et al. 2002a). Further insight into the mechanism of NAS was provided by the finding that hUpf1 plays a distinct role in NAS in addition to its known function in NMD (Mendell et al. 2002).

Suppression of splicing (SOS) is a novel nuclear scanning mechanism that prevents splicing at intronic latent $5^{\prime}$ splice sites, which would lead to the inclusion of a stop codon, if said splicing was allowed to take place. We first noticed this phenomenon upon the discovery that a latent $5^{\prime}$ splice site in the $C A D$ gene is activated after heat shock (Miriami et al. 1994). We also conducted a survey of a database consisting of 2311 introns from 446 human protein-coding-genes, in which we identified 10,490 latent $5^{\prime}$ splice sites (Miriami et al. 2002, 2004). In most cases, the lack of splicing at the latent sites could be correlated with the occurrence of upstream in-frame stop codons, indicating a general role for SOS in maintaining the translatability of mRNAs.

We previously verified the existence of the SOS mechanism in transfection experiments using two gene systems: (1) $C A D$, the gene encoding the housekeeping multifunc-

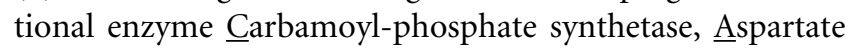
trans-carbamylase, Dihydroorotase (Padgett et al. 1982), and (2) IDUA, the gene encoding the human lysosomal enzyme $\alpha$-L-iduronidase, mutations in which are the cause of a group of lysosomal disorders, the most severe of which is the Hurler syndrome (Neufeld 1991). We have thus shown that splicing of pre-mRNAs transcribed in vivo from mutant CAD and IDUA minigenes, in which the intronic in-frame stop codons were replaced by sense codons or eliminated by frame-shift mutations, occurred at both the normal and the latent sites, whereas splicing of the wildtype pre-mRNAs occurred exclusively at the normal $5^{\prime}$ splice site ( $\mathrm{Li}$ et al. 2002). The eliciting of latent splicing in the frame-shifted mutants, and the absence of latent splicing in nonsense to nonsense mutants (e.g., TGA to TAA) (Li et al. 2002), excluded the possibility that the observed splicing patterns could be attributed to modulation of splicing control elements (for references see Cartegni et al. 2002).

Another possible interpretation of our results is that latent splicing normally occurs, but the latent RNA is subjected to rapid degradation by NMD. In this paper we exclude this possibility and show that SOS is distinct from NMD. This is because latent splicing is activated neither by translation inhibitors nor by down-regulation of the NMDassociated genes, hUpf1 and hUpf2, by RNA interference (RNAi). We also show here that SOS is distinct from NAS because a hUpf1 mutant that abrogates both NMD and NAS (Mendell et al. 2002) did not activate latent splicing.

\section{RESULTS}

\section{Latent splicing is not activated by $\mathrm{CHX}$-an inhibitor of translation known to abrogate NMD}

Under normal growth conditions, splicing events involving latent $5^{\prime}$ splice sites have not been reported, although such latent sites are highly abundant in introns (Miriami et al. 2002 , 2004). We previously employed a highly sensitive RTPCR procedure to show that splicing involving a latent $5^{\prime}$ splice site in the wild-type CAD and IDUA genes (Fig. 1) is fully suppressed by the nonsense-codon-mediated SOS mechanism ( $\mathrm{Li}$ et al. 2002). To examine the possibility that latent splicing normally occurs in pre-mRNAs derived from constructs harboring in-frame stop codons, but the resulting nonsense mRNA is subject to a rapid and complete degradation by the NMD pathway, we tested the effect of the translation inhibitor cycloheximide (CHX) on latent splicing. CHX was shown to inhibit NMD by reversing the down-regulatory effects of exonic PTCs (Carter et al. 1995; Rajavel and Neufeld 2001). Here we show that treatment with CHX of cells transfected with IDUA wild type (WT), which harbors an in-frame stop codon between the normal and the latent site (see Fig. 1), did not reveal latent splicing even after $270 \mathrm{~min}$ of treatment (Fig. 2A, lanes 1-4). In comparison, we show that when the stop codon was eliminated (a TGA to TGG mutation; IDUA Mut1), latent splicing was activated but the level of the latent RNA was not affected by the drug (Fig. 2A, lanes $5-8$ ). As a positive 

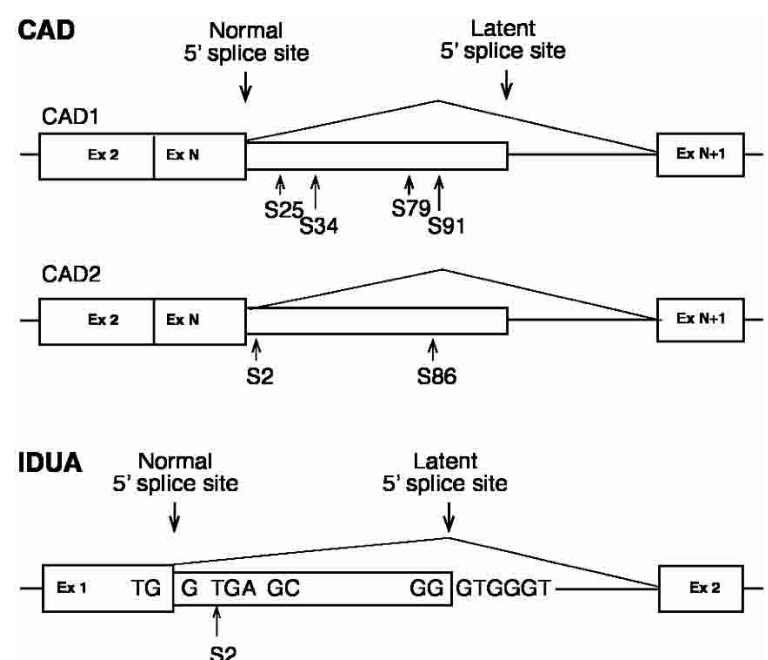

s2

FIGURE 1. Schematic drawings of wild-type CAD and IDUA minigene constructs. Open boxes, exons; lines, introns; narrow boxes, intronic sequence included as part of the exon in latent RNA; diagonal lines, normal splicing patterns. The normal and latent 5 ' splice sites are indicated. The in-frame stop codons are indicated ( $\mathrm{S \#}$ designates the $\mathrm{T}$ nucleotide in a stop codon and its respective distance from the normal 5' splice site).

control we show that under the same conditions NMD is abrogated. Thus, $\beta$-globin nonsense RNA expressed from pmCMV-Gl-39Ter, which harbors a PTC within a bona fide exon (Zhang et al. 1998), was up-regulated upon treatment with CHX (Fig. 2B, lanes 4-6), whereas the levels of wildtype $\beta$-globin did not change (Fig. 2B, lanes $1-3$ ). These results complement our previous observation that treatment with CHX did not elicit latent splicing in the wild-type CAD pre-mRNA (Li et al. 2002).

\section{Latent splicing is not activated by G-418-a drug that enables translation read-through}

To further test whether the complete absence of latent splicing was not due to NMD, we used the aminoglycoside antibiotic G-418. This drug is known to abrogate NMD by allowing translation read-through of PTC-containing RNAs (Bedwell et al. 1997). Thus, cells transfected with IDUA minigenes were treated with different concentrations of G-418 for $18 \mathrm{~h}$. Here again, latent splicing was not detected in cells transfected with IDUA WT (Fig. 2C, lanes 1-4) even at a G-418 concentration of $200 \mu \mathrm{g} / \mathrm{mL}$. In contrast, latent splicing in IDUA Mut1, which lacks in-frame stop codons, was activated (Fig. 2C, lanes 5-8), whereas the levels of latent RNA were not significantly affected by the G-418 treatment. As a positive control we show that upon treatment with G-418, under the same conditions, NMD is abrogated. As expected, the level of nonsense $\beta$-globin mRNA was up-regulated (Fig. 2D, lanes 4-6), whereas there was no change in wild-type levels (Fig. 2D, lanes 1-3).

\section{Latent splicing is not elicited by cognate suppressor tRNAs}

Suppressor tRNAs enable translational read-through of nonsense mRNAs that contain the cognate PTCs, and were previously shown to be an effective means of abrogating NMD (Li et al. 1997). To test whether suppressor tRNAs can elicit latent splicing, we cotransfected each of three different constructs of CAD mutants derived from CAD2 (Fig. 1, CAD), each having a different stop codon at $\mathrm{S} 86$ (TGA, CAD Mut2; TAG, CAD Mut10; TAA, CAD Mut11), with the cognate suppressor tRNA. As can be seen in Figure $3 \mathrm{~A}$, no latent splicing was observed in RNAs arising from these transfections (Fig. 3A, lanes 1-9), whereas in transfection experiments using CAD Mut12, in which the TGA stop codon at S86 was mutated to TGG (lanes 10-12), the expected latent splicing was observed, and was not affected by cotransfection with suppressor tRNA. The absence of latent splicing in the stop codon-containing RNAs was further confirmed by Southern blot RT-PCR analysis (Fig. 3B).

Cotransfection experiments with the cognate suppressor tRNA were also performed with the wild-type IDUA construct (Fig. 3C, lanes 1-2). Here again, latent splicing was not obtained, as expected for SOS in pre-mRNAs that harbor intronic in-frame stop codons upstream of a latent $5^{\prime}$ splice site. For comparison, we show the splicing pattern of RNA expressed from an IDUA mutant that lacks in-frame stop codons ( $\mathrm{Li}$ et al. 2002), which gave rise to a 447-nt PCR fragment representing latent RNA (Fig. 3C, lane 3). As a control we tested the effect of suppressor tRNA on the expression of $\beta$-globin nonsense RNA. Cotransfection with wild-type $\beta$-globin, with or without suppressor tRNA, gave rise to similar levels of $\beta$-globin RNA (Fig. 3D, lanes 1,2). Transfection with pmCMV-Gl-39Ter alone gave rise to a low level of the nonsense $\beta$-globin RNA (Fig. 3D, lane 3), which was up-regulated to almost the wild-type level by cotransfection with the cognate suppressor tRNA (Fig. 3D, lane 4).

\section{Latent splicing is not elicited by a dominant negative mutant of hUpf1}

Human Upf1 is one of a number of proteins directly involved in the NMD pathway (Sun et al. 1998; LykkeAndersen et al. 2000, 2001; Mendell et al. 2002). A dominant negative mutant of hUpfl, in which an arginine at residue 844 was mutated to cysteine (hUpf1 R844C), was shown to inhibit NMD (Sun et al. 1998; Lykke-Andersen et al. 2000). We could therefore test directly whether the absence of latent splicing could be attributable to NMD in cotransfection experiments with either wild-type or hUpf1 R844C (dominant negative) mutant constructs. For the CAD system we used two stop codon-containing constructs: (1) the wild-type construct CAD1, which harbors four inframe stop codons upstream of the latent $5^{\prime}$ splice site (Fig. 
A

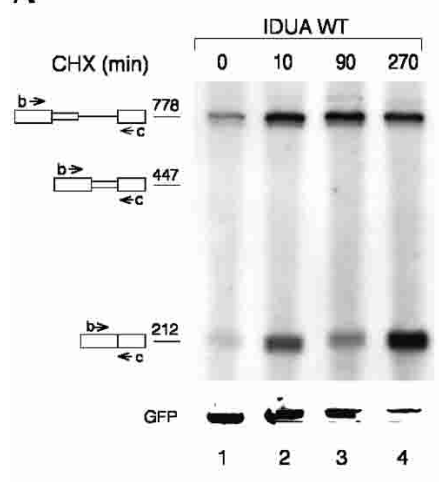

B

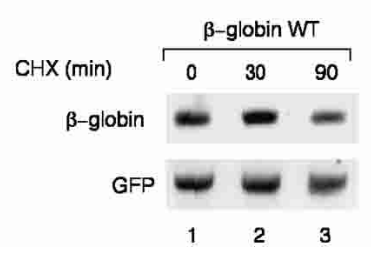

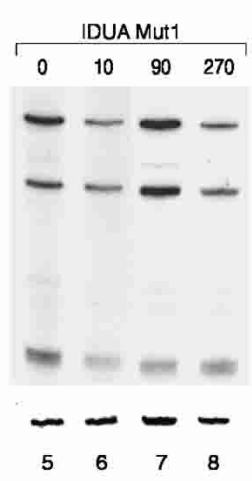

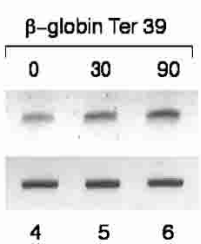

C
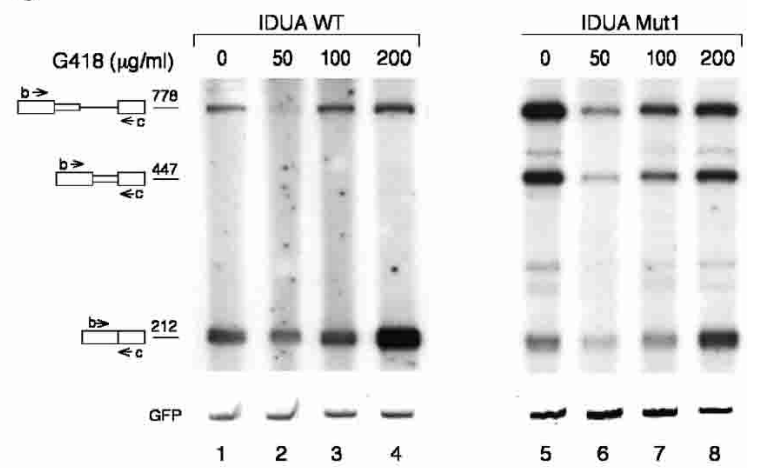

D

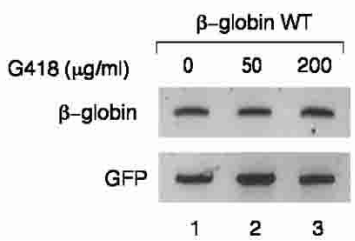

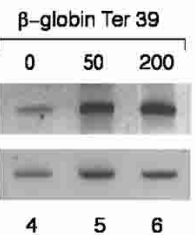

FIGURE 2. Treatment with cycloheximide (CHX) and G-418 does not affect latent splicing. Human 293T cells were cotransfected with GFP and with either IDUA wild-type construct or with IDUA Mut1 (a construct lacking in-frame stop codons) as indicated. In parallel, cells were cotransfected with GFP and with either wild-type or mutant $\beta$-globin constructs, as indicated. $(A, B)$ Twenty-four h post-transfection, the cell cultures were treated with $\mathrm{CHX}$ at $20 \mu \mathrm{g} / \mathrm{mL}$ for the indicated lengths of time. $(C, D)$ Cells treated with increasing levels of G-418 for $18 \mathrm{~h}$. RT-PCR was performed with primers $b+c$, for IDUA. Results are representative of three independently performed experiments. Bands corresponding to precursor and mature (normal and latent) IDUA fragments are indicated by schematic drawings on the left. The assignments of bands were verified by DNA sequencing.

1, CAD), and (2) CAD Mut25, a new construct derived from $\mathrm{CAD} 1$ by a $\mathrm{T}$ insertion at position 25 , which frameshifted the four in-frame stop codons and introduced a new one at position 45 (see heading of Fig. 4A). Figure 4A shows that latent splicing does not occur in CAD transcripts harboring either four in-frame stop codons (CAD1, lane 1) or one in-frame stop codon positioned in a different location (Mut25, lane 4). Cotransfection of stop codon-harboring CAD constructs with either wild-type hUpf1 (lanes 2,5) or with the dominant negative mutant of hUpf1 (lanes 3,6 ) did not activate latent splicing in RNA expressed from the respective constructs. As a control we show that in transfection experiments using CAD Mut9, in which all stop codons had been removed, the expected latent splicing was observed (lanes 7-9).

We also tested the effect of hUpf1 on latent splicing of IDUA pre-mRNA. Figure $4 \mathrm{~B}$ shows that latent splicing did not occur in the stop codon-containing IDUA wild-type pre-mRNA, whether untreated (Fig. 4B, lane 2), or treated with either wild-type or mutant hUpf1 constructs (lanes 3,4 , respectively). To show that NMD is abrogated under these conditions, we cotransfected $\beta$-globin constructs with the hUpf1 constructs. Transfection with $\beta$-globin Ter39 alone gave rise to a low level of the nonsense $\beta$-globin RNA (Fig. 4C, lane 4) relative to that of the wild-type RNA (Fig. $4 \mathrm{C}$, lane 1). This level remained unchanged in cotransfection with wild-type hUpf1 (Fig. 4C, lane 5), but was up- regulated by the dominant negative mutant of hUpf1 (Fig. $4 \mathrm{C}$, lane 6).

\section{Latent splicing is not activated by down-regulation of hUpf1 and hUpf2}

Although we have shown that a dominant negative mutant of hUpf1 is unable to activate latent splicing, in order to directly determine whether NMD factors are involved in SOS, we decided to use RNAi (Elbashir et al. 2001) to down-regulate two of the proteins involved in NMD. Previous analyses of the effect of RNAi against hUpf1 or hUpf2 on the expression of a mutant of the TCR- $\beta$ gene, which harbors a PTC, showed that hUpf1 has genetically separable functions in NMD and NAS, whereas hUpf2 has a role in NMD but not in NAS (Mendell et al. 2002).

RNAi was employed here to inhibit the expression of hUpf1 or hUpf 2 in HeLa cells, using the small interfering RNA (siRNA) duplexes described by Mendell et al. (2002). Forty-eight hours after treatment with siRNA, the cells were cotransfected with either $\beta$-globin Ter39 or CAD1 WT and GFP constructs, and with or without the hUpf1 mutant constructs (see below). Cells were harvested $24 \mathrm{~h}$ posttransfection and analyzed for proteins and RNAs. Western blot analysis revealed that RNAi of hUpf1 down-regulated its expression to $12 \%$ (Fig. 5A, lane 3), and RNAi of hUpf2 down-regulated the expression of this protein to $25 \%$ (Fig. 
5A, lane 4). As a negative control we employed RNAi against firefly luciferase. As can be seen, siRNA against luciferase did not affect the levels of hUpf1 and hUpf2 pro-
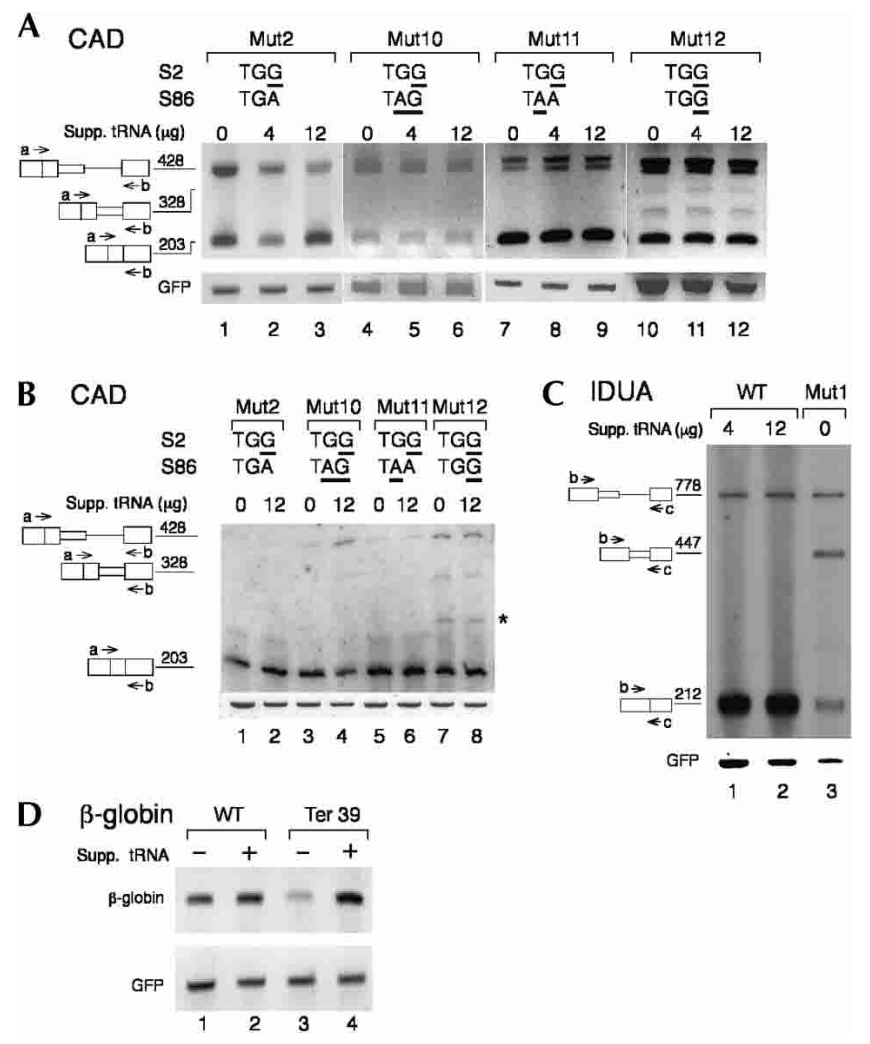

FIGURE 3. Suppressor tRNAs do not activate latent splicing. $(A)$ Constructs derived from CAD2, each having one of the three in-frame stop codon variants at S86 (Mut2, TGA; Mut10, TAG; Mut11, TAA) and a mutant in which the stop codon at S86 was mutated to a sense codon (Mut12, TGG) were each cotransfected with the indicated amounts of the cognate suppressor tRNA (amber for Mut12). CAD RNA was analyzed by RT-PCR using CAD primers $a+b$. Additional minor bands, which occasionally appeared just below the 428-nt band in this figure and in Figure 4A, were assigned to heteroduplexes, as confirmed by sequence analyses. $(B)$ Southern blot RT-PCR analysis of CAD Mut2, Mut10, and Mut11, each cotransfected with the indicated amount of the cognate suppressor tRNA (lanes 1-6). The expression of Mut12, which has no in-frame stop codon between the normal and the latent site, is shown for comparison (lanes 7,8). Longer exposures (up to five times) of lanes 1-6 did not show any latent splicing. The asterisk on the right indicates a previously observed (Miriami et al. 1994) second latent site, which is not always activated. (C) IDUA wild-type construct was cotransfected with the cognate suppressor tRNA, and the expressed RNAs were analyzed by RT-PCR (lanes 1,2). An RT-PCR analysis of RNA expressed from an IDUA mutant lacking in-frame stop codons is shown in lane 3 , to mark the position of the 447-nt band that corresponds to latent IDUA mRNA. (D) Control transfection experiments, performed in parallel with the SOS experiments, using wild-type and Ter39 $\beta$-globin constructs, showing that the cognate suppressor tRNA abrogates NMD under the same conditions. Results are representative of three independently performed experiments. Bands corresponding to precursor and mature (normal and latent) $\mathrm{CAD}$ and IDUA fragments are indicated by schematic drawings on the left. The assignments of bands were verified by DNA sequencing. Coexpressed GFP mRNA was used as an internal reference in all experiments. teins (Fig. 5A, lane 2). Further controls show that RNAi against luciferase had no effect on the expression of $\beta$-globin Ter39, nor on the expression of both endogenous hUpf1 and hUpf2 RNAs (Fig. 5B, lanes 1,2). The same treatment had no effect on the expression of CAD1 and the endogenous hUpf1 and hUpf2 RNAs (Fig. 5B, lanes 3,4).

The effect of down-regulation of hUpf1 on NMD was tested using the $\beta$-globin Ter39 construct. The low level of expression of $\beta$-globin Ter39 (10\%-20\% of wild-type $\beta$-globin; see Figs. $2 \mathrm{~B}, \mathrm{D}, 3 \mathrm{D}, 4 \mathrm{C}$ ) was up-regulated threeto fivefold upon RNAi treatment of hUpf1 (Fig. 6A, lanes 1 and 2, respectively), indicating that NMD was abrogated. RT-PCR analysis of hUpf1 mRNA, expressed in the same cells, revealed that hUpf1 mRNA was almost completely knocked down (Fig. 6A, cf. lanes 6,7). To confirm this result, we complemented the hUpf1 RNAi-treated cells with the hUpf1 mutants of Mendell et al. (2002) (kindly provided by J. Mendell, Johns Hopkins), and tested their effect on the expression of $\beta$-globin Ter39 mRNA. Cotransfection with hUpf1 R1 ${ }^{\mathrm{R}}$ (a hUpf1 construct harboring a silent mutation at the siRNA targeting site, rendering it resistant to RNAi) restored the down-regulation of $\beta$-globin Ter39 mRNA (Fig. 6A, lane 3), indicating that NMD was restored. Cotransfection with either the hUpf1 mutant $\mathrm{R}^{\mathrm{R}}{ }^{\text {- }}$ DE637AA, which abrogates only NMD, or with the hUpf1 mutant R1 ${ }^{\mathrm{R}}$-RR857AA, which abrogates both NAS and NMD, resulted in increased expression of $\beta$-globin Ter39 mRNA (Fig. 6A, lanes 4,5). In accordance with the abovementioned results, we show that hUpf1 mRNAs were expressed from the respective mutant constructs (Fig. 6A, upper panel, lanes 8-10). To distinguish this expression from that of the wild-type endogenous hUpf1, we subjected the hUpf1 RT-PCR products to the restriction enzyme PsuI. This enzyme cleaves only the RT-PCR products amplified from the mRNA of the hUpf1 mutants, but not those obtained from the mRNA of the endogenous hUpf1. As can be seen (Fig. 6A, right, middle panel), the level of expression of the endogenous hUpfl, without siRNA treatment and cotransfection, did not change upon PsuI treatment (lane 6), but was significantly down-regulated by the siRNA treatment even upon coexpression of the mutant constructs (lanes 8-10).

Next we tested the effect of down-regulation of hUpf1 on the splicing pattern of wild-type CAD1 pre-mRNA under conditions identical to those used for the $\beta$-globin Ter39 experiments. If NMD were responsible for the absence of latent splicing in pre-mRNA expressed from the CAD WT construct without any treatment (Fig. 6B, lane 1), latent mRNA should have been revealed after treatment with siRNA. It can, however, be seen that although the expression of hUpf1 was virtually completely abolished (Fig. 6B, lane 8), latent splicing in the WT CAD pre-mRNA was not detected (Fig. 6B, lane 2). The characteristic absence of latent splicing remained unchanged in complementation experiments with the hUpf1 mutant $\mathrm{R} 1^{\mathrm{R}}$-DE637AA, which 

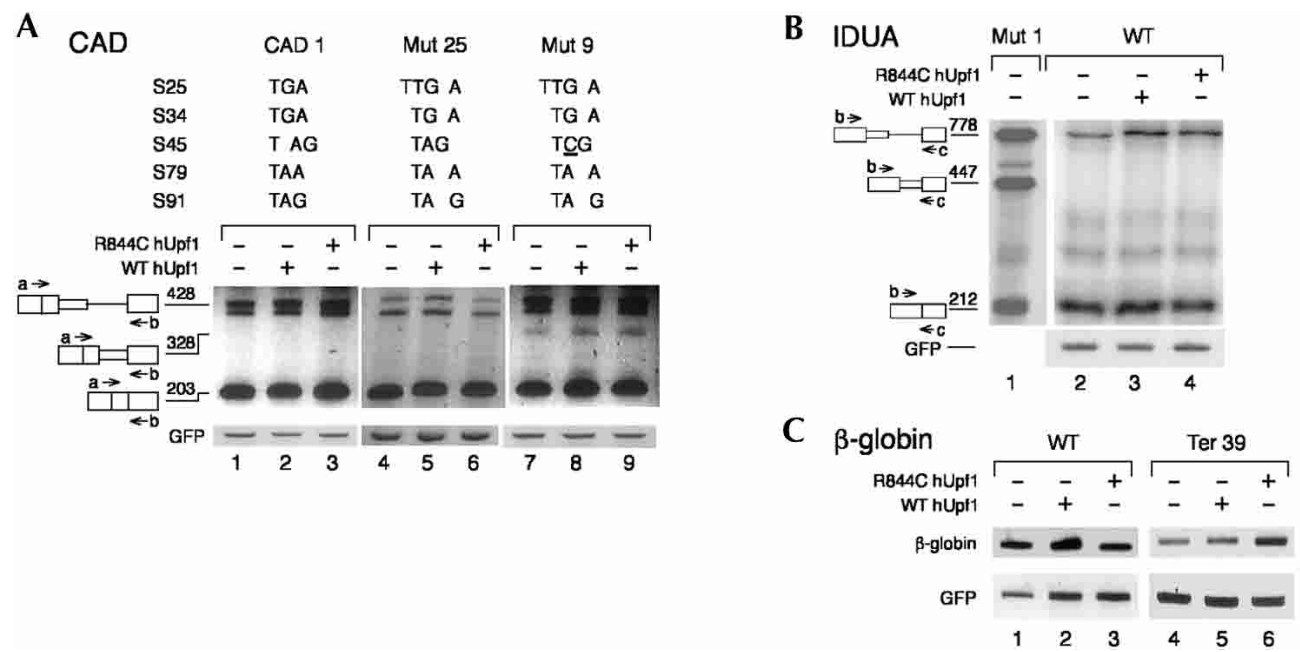

FIGURE 4. A dominant negative mutant of hUpf1 is unable to activate latent splicing. (A) CAD1 (the wild-type CAD construct having four in-frame stop codons), CAD Mut25 (a construct with one in-frame stop codon at S45), and CAD Mut9 (a construct lacking all in-frame stop codons) were each cotransfected with or without either the wild-type or the dominant negative mutant of hUpf1 into 293T cells as indicated. Total RNA was isolated and analyzed by RT-PCR. (B) IDUA wild-type construct was cotransfected with either the wild-type or the dominant negative mutant of hUpf1 into $293 \mathrm{~T}$ cells as indicated (lanes 2-4). Total RNA was isolated and analyzed by RT-PCR. An RT-PCR analysis of RNA expressed from an IDUA mutant lacking in-frame stop codons (Mut1) is shown in lane 1, to mark the position of the 447-nt band that corresponds to latent IDUA mRNA. $(C)$ Control transfection experiments using wild-type and $\beta$-globin Ter39 constructs, showing that cotransfection with the dominant negative mutant of hUpf1 (R844C, lane 6) abrogates NMD under the same conditions. The assignments of bands were verified by DNA sequencing. Co-expressed GFP mRNA was used as an internal reference in all experiments. Results are representative of at least three independently performed experiments, each performed with the $\beta$-globin, CAD, and IDUA constructs in parallel. Lettering and symbols are as in Figure 3.

abrogates only NMD, and in those with the hUpf1 mutant $\mathrm{R} 1^{\mathrm{R}}$-RR857AA, which abrogates both NAS and NMD (Fig. 6B, lanes 3-5,9-11). For comparison, we show latent CAD mRNA expressed from CAD Mut9 (Fig. 6B, lane 6), a mutant in which the in-frame stop codons were removed by frame-shifting (Li et al. 2002). No latent splicing could be detected in similar experiments (data not shown) testing the effect of down-regulation of hUpf1 by RNAi on the expression of WT CAD2 (a construct harboring two in-frame stop codons between the normal and latent $5^{\prime}$ splice site; see Fig. 1). The absence of latent splicing in RNA expressed from the wild-type CAD construct treated with RNAi against hUpf1 was further confirmed by Southern blot RT-PCR analysis (Fig. 6C).

We further tested the effect of down-regulation of hUpf2 on SOS in CAD pre-mRNA. Using the $\beta$-globin Ter39 construct, we first show that down-regulation of hUpf 2 abrogated NMD because the low level of expression of $\beta$-globin Ter39 (10\%-20\% of wild-type $\beta$-globin; see Figs. 2B,D, 3D, $4 \mathrm{C})$ was up-regulated threefold upon RNAi treatment of hUpf2 (Fig. 7A, lanes 1 and 2, respectively). RT-PCR analysis of hUpf 2 mRNA, expressed in the same cells, confirmed that hUpf 2 mRNA was almost completely knocked down (Fig. 7A, cf. lanes 3,4). Here again, if NMD were responsible for the absence of latent splicing in pre-mRNA expressed from the CAD WT construct without any treatment (Fig. $7 \mathrm{~B}$, lane 1), latent mRNA should have been revealed after treatment with siRNA to hUpf2. It can, however, be seen that although the expression of hUpf2 was virtually completely abolished (Fig. 7B, lane 5), latent splicing in the WT CAD pre-mRNA was not detected (Fig. 7B, lane 2). For comparison, we show latent CAD mRNA expressed from CAD Mut9 (Fig. 7B, lane 3), a mutant in which the in-frame stop codons were removed by frame-shifting ( $\mathrm{Li}$ et al. 2002). The absence of latent splicing in RNA expressed from the wild-type CAD construct treated with RNAi against hUpf2 was further confirmed by Southern blot RTPCR analysis (Fig. 7C). It can thus be concluded that SOS is distinct from NMD also with respect to the involvement of hUpf2 in these mechanisms.

\section{DISCUSSION}

Suppression of splicing (SOS) is an RNA surveillance mechanism required to sustain normal gene expression. It is vital to discriminate between authentic $5^{\prime}$ splice sites and latent $5^{\prime}$ splice sites, which are highly abundant particularly in introns. SOS presumably prevents splicing at intronic latent $5^{\prime}$ splice sites because splicing at most of these sites would introduce nonsense codons into the resultant mRNAs (Miriami et al. 1994, 2002; Li et al. 2002). We previously demonstrated the occurrence of SOS in two gene systems, $C A D$ and IDUA, by eliciting splicing at latent $5^{\prime}$ splice sites in minigenes in which in-frame stop codons upstream of the latent $5^{\prime}$ splice sites were eliminated (Li et al. 2002). These results were further supported by compu- 
A

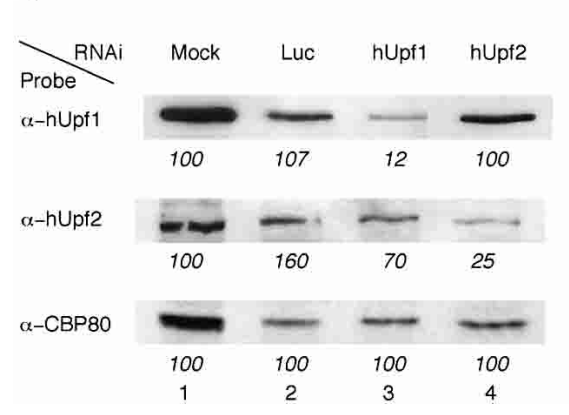

\section{B}

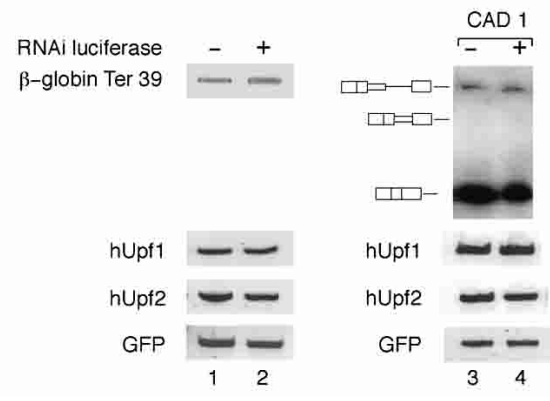

which is dependent on translation (Frischmeyer and Dietz 1999; Maquat 2002), SOS appears to be independent. This is evidenced by the following observations. (1) Latent splicing is not activated by the protein synthesis inhibitor CHX, as previously shown for the wildtype CAD gene (Li et al. 2002) and here for the wild-type IDUA gene (Fig. 2A), whereas CHX was shown to abrogate NMD (Carter et al. 1995; Rajavel and Neufeld 2001). (2) Latent splicing is not activated by the aminoglycoside antibiotic G-418, which allows stop codon read-through and was shown to abrogate NMD (Bedwell et al. 1997). (3) Suppressor tRNAs, although able to abrogate NMD (Li et al. 1997), are unable to activate latent splicing.

The second line of evidence, which more decisively demonstrates the distinction of SOS from NMD, emerges from the analyses of the effects of hUpf1 and hUpf 2 on latent splicing. It has been

tational analyses, thereby making a strong case for the generality of the SOS phenomenon (Miriami et al. 2002, 2004). The occurrence of SOS invokes a mechanism that can recognize the mRNA reading frame at the level of pre-mRNA and suppress splicing events that would lead to the production of nonsense mRNAs. How such recognition is brought about is not yet understood.

Although latent $5^{\prime}$ splice sites are highly abundant-an average of $\sim$ six latent sites per authentic one (Miriami et al. 2002)-splicings that involve such sites under normal conditions have not yet been reported. Thus, regulation of splicing by SOS appears to be extremely tight. Despite repeated efforts to detect latent splicing expressed from CAD and IDUA minigene constructs that harbor in-frame stop codons upstream of the latent sites, we observed no latent splicing even by highly sensitive S1 nuclease mapping and quantitative RT-PCR methods. Using quantitative RT-PCR analyses, we previously estimated that the lower limit for detecting latent splicing was more than four orders of magnitude smaller than the level of normal splicing ( $\mathrm{Li}$ et al. 2002). This analysis means that splicing involving latent $5^{\prime}$ splice sites is practically zero, and thus latent splicing can be considered a de novo event rather than an increase in the level of a pre-existing event (see following discussion on NMD).

Although latent splicing cannot be detected under normal growth conditions, one could propose that latent splicing is in fact occurring, but the resulting nonsense RNA is subject to rapid degradation through the NMD pathway. Here we rule out this possibility by showing that SOS is distinct from NMD in several aspects. First, unlike NMD, established that the hUpf proteins (hUpf1, hUpf2, hUpf3a, and hUpf $3 b$ ) directly mediate NMD in human cells (Sun et al. 1998; Lykke-Andersen et al. 2000; Mendell et al. 2002; Wang et al. 2002b). The hUpf proteins cooperate with the exon junction complex (EJC) to identify PTC-harboring mRNAs and trigger the NMD response (Kim et al. 2001; Le Hir et al. 2001; Lykke-Andersen et al. 2001; Gehring et al. 2003; Ohnishi et al. 2003). In view of the central role that the hUpf proteins play in NMD, we first tested the effect on latent splicing of a dominant negative mutant of hUpf1, which is known to abrogate NMD (Sun et al. 1998; LykkeAndersen et al. 2000). Here we show that latent splicing in wild-type CAD and IDUA constructs is not activated by cotransfection with the dominant negative mutant of hUpfl, whereas under the same conditions NMD is abrogated in a $\beta$-globin mRNA harboring a PTC in a bona fide exon. Finally, based on the finding that depleting hUpf1 and hUpf2 by RNAi abrogated NMD in TCR- $\beta$ pre-mRNA, which indicated the direct involvement of these proteins in NMD (Mendell et al. 2002), we tested the effect of such depletion on latent splicing. Here again, down-regulation of either hUpf1 or hUpf 2 by siRNAs abrogated NMD of $\beta$-globin Ter39 mRNA, but did not activate latent splicing in wild-type CAD pre-mRNA (Figs. 6 and 7, respectively).

NAS is another RNA surveillance mechanism proposed to involve a nuclear scanning mechanism (Hentze and $\mathrm{Ku}$ lozik 1999). Although some cases of NAS have been attributed to modulation of splicing control elements, other cases cannot be explained this way (see Introduction). Likewise, modulation of splicing control elements cannot account for the induction of splicing at latent sites when stop codons 
A
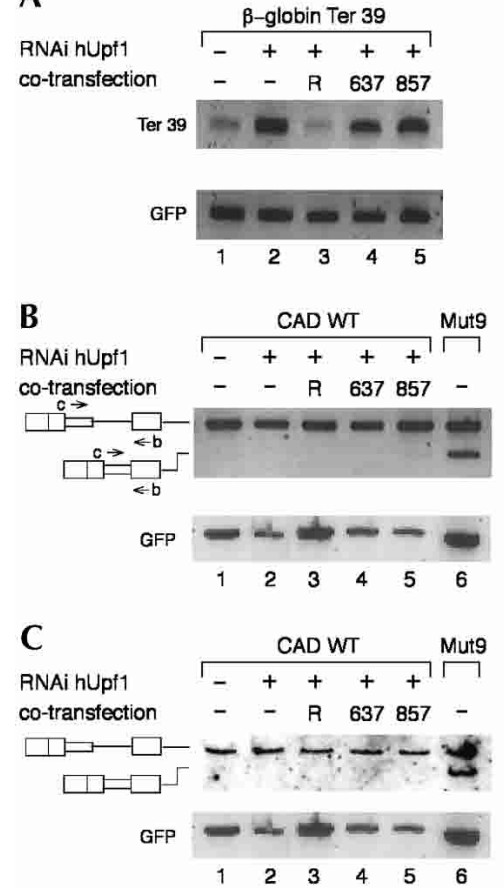

FIGURE 6. Down-regulation of hUpf1 by RNAi does not activate latent splicing. (A) RT-PCR analysis of $\beta$-globin Ter39, GFP, and hUpf1 RNAs prepared from cells that were treated with siRNA against hUpfl, and cotransfected with $\beta$-globin Ter39 constructs, GFP, and with or without each of the hUpf1 mutant constructs resistant to RNAi [R1 $1^{\mathrm{R}}, \mathrm{R} 1^{\mathrm{R}}$-DE637AA (637), and R1 ${ }^{\mathrm{R}}$-RR857AA (857); see text]. PCR products of hUpf1 were treated with the restriction enzyme PsuI, which cuts only the mutant constructs, in order to differentiate between endogenous and transfected mutant hUpf1. (B) RT-PCR analysis of CAD, GFP, and hUpfl RNAs prepared from cells treated with siRNA against hUpfl, and cotransfected with CAD constructs, GFP, and with or without hUpf1 constructs resistant to RNAi as indicated. PCR products of hUpfl were treated with the restriction enzyme PsuI as in A. Lane 6 shows RT-PCR analysis of RNA expressed from CAD Mut9, a mutant lacking in-frame stop codons, to mark the position of the band that corresponds to latent CAD mRNA. Longer exposures (up to five times) of lanes 1-5 did not show any latent splicing. Results are representative of at least four independent experiments, each performed with the $\beta$-globin and CAD constructs in parallel. $(C)$ Southern blot RT-PCR analysis of the CAD RNA samples used in $B$.

upstream of such sites are mutated to sense codons. This is because nonsense to nonsense mutations retained the characteristic null occurrence of latent splicing, whereas eliminating stop codons by frame-shift mutations activated latent splicing ( $\mathrm{Li}$ et al. 2002). The question thus arises, is SOS similar to NAS? From this study we can conclude that SOS is distinct from NAS, at least the kind of NAS represented by the TCR- $\beta$ case (Mendell et al. 2002; Wang et al. 2002a). This is because Mendell et al. (2002) showed that hUpf1 has two genetically distinct functions on NAS and on NMD, which can be differentiated using two hUpf1 mutants: one that abrogates only NMD and not NAS, and one that abrogates both. When we tested the effect of each of these mutants on SOS in siRNA-depleted hUpfl cells, we found that complementation with either mutant did not activate latent splicing.
We can therefore conclude that SOS is a novel RNA surveillance mechanism, which requires nuclear scanning but is distinct from NMD and NAS. Such a surveillance mechanism is difficult to conceive, particularly because SOS is independent of protein synthesis. Based on the recent finding in the nucleus of: (1) charging of tRNA (Lund and Dahlberg 1998), (2) translation initiation factors (Dostie et al. 2000), and (3) coupled transcription and translation (Iborra et al. 2001; Brogna et al. 2002), scanning by nuclear ribosomes was proposed for NMD (Li and Wilkinson 1998; Frischmeyer and Dietz 1999; Hentze and Kulozik 1999; Maquat 2002). On the other hand, the evidence for nuclear translation was questioned recently (Nathanson et al. 2003), and an alternative explanation for NMD and NAS which does not invoke nuclear translation was proposed (Dahlberg et al. 2003). According to this model, PTCs are recognized in the cytoplasm by translating ribosomes, and this recognition triggers a feedback mechanism that affects nuclear events. Regardless, in the case of SOS, protein synthesis does not seem to be required, and the ribosome translation machinery, as defined for protein synthesis, is not expected to function in SOS. Yet, at this stage we cannot

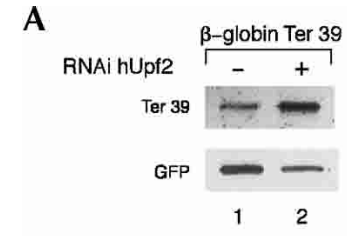

B

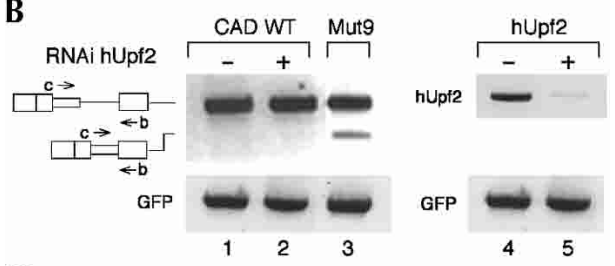

C

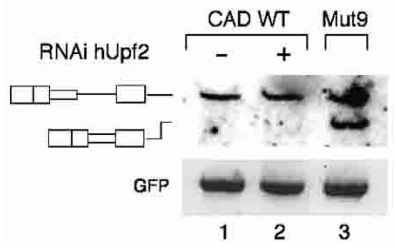

FIGURE 7. Down-regulation of hUpf2 by RNAi does not activate latent splicing. (A) RT-PCR analysis of $\beta$-globin Ter39, GFP and hUpf2 RNAs prepared from cells that were treated with siRNA against hUpf2, and cotransfected with $\beta$-globin Ter39 constructs, GFP, and with or without the hUpf2 construct. (B) RT-PCR analysis of CAD, GFP, and hUpf2 RNAs prepared from cells treated with siRNA against hUpf2, and cotransfected with the CAD1 construct, GFP, and with or without hUpf 2 construct. Lane 3 shows RT-PCR analysis of RNA expressed from CAD Mut9, a mutant lacking in-frame stop codons, to mark the position of the band that corresponds to latent CAD mRNA. Longer exposures (up to five times) of lanes 1,2 did not show any latent splicing. Results are representative of five independent experiments, each performed with the $\beta$-globin and CAD constructs in parallel. $(C)$ Southern blot RT-PCR analysis of the CAD RNA samples used in $B$. 
exclude the involvement of individual ribosomal components in SOS.

Whatever the nature of the nuclear scanning machine is, questions remain regarding how can it recognize the reading frame of the mRNA while introns, whose length is not necessarily an integer multiple of three, are still present. We previously proposed that the supraspliceosome, in which nuclear pre-mRNAs are assembled and processed (Müller et al. 1998; Medalia et al. 2002), might perform this task (Miriami et al. 1994; Li et al. 2002). Hence, the supraspliceosome serves as a frame onto which the pre-mRNA is folded to align exons about to be spliced, while introns are looped out of each of the respective spliceosomes. This configuration allows exon sequences to be scanned consecutively even when introns are still part of the pre-mRNA. Thus, if the pre-mRNA is arranged on the supraspliceosome in such a manner that a latent $5^{\prime}$ splice site is aligned to the downstream 3 ' splice site, the SOS mechanism will recognize the presence of an in-frame stop codon and suppress splicing at this site. This situation would facilitate the rearrangement of the pre-mRNA to a conformation in which the normal $5^{\prime}$ splice site is juxtaposed to the downstream $3^{\prime}$ splice site. The latter alignment will be approved by the SOS mechanism, due to the absence of upstream in-frame stop codons, and splicing will proceed.

\section{MATERIALS AND METHODS}

\section{Plasmids}

Wild-type and mutant CAD and IDUA minigene constructs were described by Li et al. (2002). CAD mutant 25 (Mut25) was prepared using the QuickChange PCR-based mutagenesis method (Stratagene). It was derived from the wild-type construct CAD1 by a frame-shift mutation that eliminated the four intronic in-frame stop codons, and introduced a new in-frame stop codon $45 \mathrm{nt}$ downstream of the authentic 5' splice site (S45). All constructs were confirmed by DNA sequence analysis.

Wild-type hUpf1 and the construct expressing a dominant negative hUpf1 mutant (hUpf1 R844C) (Lykke-Andersen et al. 2000) were kindly provided by Dr. Jens Lykke-Andersen (University of Colorado). hUpf1 R1 ${ }^{\mathrm{R}}$, hUpf1 R1 $1^{\mathrm{R}}$-DE637AA, and hUpf1 $\mathrm{R} 1^{\mathrm{R}}$-RR857AA (Mendell et al. 2002) were kindly provided by Drs. Joshua Mendell and Harry Dietz (Johns Hopkins). Suppressor tRNA constructs, pUCtSam-human serine amber suppressor UAG, pUCtSoc-ochre suppressor UAA, and pUCtSop-opal suppressor UGA (Li et al. 1997) were kindly provided by Dr. Miles Wilkinson (University of Texas, Houston). Nonsense-free and nonsense-containing $\beta$-globin construct (pmCMV-Gl-Norm and pmCMV-Gl-39Ter, respectively; Zhang et al. 1998) were kindly provided by Dr. Lynne E. Maquat (University of Rochester).

\section{Transfections}

Human $293 \mathrm{~T}$ or HeLa cells were grown to $50 \%$ confluency in tissue culture plates as described ( $\mathrm{Li}$ et al. 2002) and transiently cotransfected with the appropriate test DNA constructs $(2-10 \mu \mathrm{g}$ per $5 \times 10^{6}$ cells) and pEGFP-N3 (Clontech) $\left(1 \mu \mathrm{g}\right.$ per $5 \times 10^{6}$ cells), using the calcium phosphate method (Kingston 1992). Treatment with CHX was as described (Li et al. 2002). Treatment with G-418 was for $18 \mathrm{~h}$ with the amounts indicated in the figure legends. The experiments with suppressor tRNAs were performed by cotransfection of $293 \mathrm{~T}$ cells with the test DNA construct, the cognate suppressor tRNA at 4 or $12 \mu \mathrm{g}$ per $5 \times 10^{6}$ cells, and pEGFP-N3. In the experiments testing the effect of the dominant negative mutant of hupf1, 293T cells were cotransfected with the test DNA construct, the appropriate hUpfl construct at $8 \mu \mathrm{g}$ per $5 \times 10^{6}$ cells, and pEGFP-N3. Cells were harvested 24 or $48 \mathrm{~h}$ after transfection, and total cellular RNA was prepared as previously described (Li et al. 2002).

\section{Small interfering RNA-mediated down-regulation of hUpf1 and hUpf2}

SiRNAs targeted to hUpf1 and hUpf2 were those described by Mendell et al. (2002), and those targeted to firefly luciferase were identical to GL2 duplexes described by Elbashir et al. (2001). They were purchased from Dharmacon and annealed according to the manufacturer's recommendations. HeLa cells were grown to $30 \%$ $50 \%$ confluency in $6-\mathrm{cm}$ plates, in DMEM medium without antibiotics, and siRNA was transfected using oligofectamine (Invitrogen) according to the company's instructions. After $48 \mathrm{~h}$, the medium was replaced by medium with antibiotics and the cells were transfected with the appropriate $\mathrm{CAD}$ or $\beta$-globin constructs for $24 \mathrm{~h}$. For complementation experiments with the hUpf1 mutant constructs $\left(\mathrm{R} 1^{\mathrm{R}}, \mathrm{R} 1^{\mathrm{R}}\right.$-DE637AA, and $\mathrm{R} 1^{\mathrm{R}}$-RR857AA), siRNAtreated cells were cotransfected with $3 \mu \mathrm{g}$ of the appropriate hUpf1 mutant construct.

\section{Western blots}

Total proteins were analyzed by $6 \%$ PAGE/SDS, blotted, and probed with antibodies against Upf1 (kindly provided by Drs. Joshua Mendell and Harry Dietz, Johns Hopkins), Upf2 (kindly provided by Dr. Jens Lykke-Andersen, Univ. of Colorado), and CBP80 (kindly provided by Dr. Ian Mattaj, EMBL).

\section{RT-PCR analyses}

Total RNA was prepared and analyzed by RT-PCR as described (Li et al. 2002). For the analyses of IDUA RNA, the primer for the RT reaction was complementary to the SP6 promoter (SP6 primer). Radioactive PCR was performed using $5^{\prime}{ }^{32} \mathrm{P}$-labeled primer $\mathrm{c}$, and analyzed by electrophoresis on $5 \%$ polyacrylamide/7M urea denaturing gels and autoradiography. For the Southern blot RT-PCR analysis, PCR was performed using CAD primers a and $\mathrm{b}$ as described (Li et al. 2002). PCR products were run on a $10 \%$ polyacrylamide/7M urea denaturing gels and transferred to GeneScreen Plus membrane (NEN Life Sciences) by semi-dry electroblotting. Membranes were crosslinked by UV light and hybridized with a $\gamma-{ }^{32} \mathrm{P}$ labeled antisense $\mathrm{CAD}$ oligonucleotide $\left[5^{\prime}\right.$-ac gaagagtttggtgcacttgatg- $3^{\prime}$, primer 6 in (Li et al. 2002; supplementary material)].

PCR analysis of hUpf1 mRNA was done using the following 
primers: hUpf1 sense: $5^{\prime}$-aggccatcgactccccggtgtcttt-3'; and hUpf1antisense: $5^{\prime}$-gtagaagatgttggatgggaaggcg- $3^{\prime}$. To differentiate the hUpf1 mRNA expressed from the endogenous gene from that expressed from the transfected mutant plasmids, half the PCR reactions were cleaned using a Nucleospin column (MachereyNagel) and digested with PsuI (MBI Fermentas). hUpf2 mRNA was analyzed by RT-PCR using the following primers: Upf2 sense: 5' -gatcttcctcaagacaaacc-3'; Upf2 antisense: 5' -gcttttgtgttcatgttcat-3'.

\section{ACKNOWLEDGMENTS}

We thank Drs. Joshua Mendell and Harry Dietz for the hUpfl mutant constructs and for antibodies against hUpf1, Drs. Joan Steitz and Jens Lykke-Andersen for the wild-type and dominant negative hUpf1 constructs and for antibodies against hUpf2, Dr. Ian Mattaj for antibodies against CBP80, Dr. Miles Wilkinson for the suppressor tRNA constructs, Dr. Lynne Maquat for the $\beta$-globin constructs, and Mrs. Aviva Pecho for excellent technical assistance. This research was supported by grants from the Israeli Ministry of Health and the Leo and Julia Forchheimer Center for Molecular Genetics at the Weizmann Institute (J.S.), from the Israel Science Foundation (R.S.), and from the Israel Ministry of Commerce and Compugen Ltd. (R.S. and J.S.).

Received April 1, 2004; accepted July 23, 2004.

\section{REFERENCES}

Aoufouchi, S., Yelamos, J., and Milstein, C. 1996. Nonsense mutations inhibit RNA splicing in a cell-free system: Recognition of mutant codon is independent of protein synthesis. Cell 85: 415-422.

Bedwell, D.M., Kaenjak, A., Benos, D.J., Bebok, Z., Bubien, J.K., Hong, J., Tousson, A., Clancy, J.P., and Sorscher, E.J. 1997. Suppression of a CFTR premature stop mutation in a bronchial epithelial cell line. Nat. Med. 3: 1280-1284.

Brogna, S., Sato, T.A., and Rosbash, M. 2002. Ribosome components are associated with sites of transcription. Mol. Cell 10: 93-104.

Brow, D.A. 2002. Allosteric cascade of spliceosome activation. Annu. Rev. Genet. 36: 333-360.

Burge, C.B., Tuschl, T.H., and Sharp, P.A. 1999. Splicing of precursors to mRNAs by the spliceosomes. In The RNA world, $2 \mathrm{~d}$ ed. (eds. R.F. Gesteland et al.), pp. 525-560. Cold Spring Harbor Laboratory Press, Cold Spring Harbor, NY.

Caputi, M., Kendzior, R.J., Jr., and Beemon, K.L. 2002. A nonsense mutation in the fibrillin-1 gene of a Marfan syndrome patient induces NMD and disrupts an exonic splicing enhancer. Genes \& Dev. 16: 1754-1759.

Cartegni, L., Chew, S.L., and Krainer, A.R. 2002. Listening to silence and understanding nonsense: Exonic mutations that affect splicing. Nat. Rev. Genet. 3: 285-298.

Carter, M.S., Doskow, J., Morris, P., Li, S., Nhim, R.P., Sandstedt, S., and Wilkinson, M.F. 1995. A regulatory mechanism that detects premature nonsense codons in T-cell receptor transcripts in vivo is reversed by protein synthesis inhibitors in vitro. J. Biol. Chem. 270: 28995-29003.

Culbertson, M.R. 1999. RNA surveillance. Trends Genet. 15: 74-80.

Dahlberg, J.E., Lund, E., and Goodwin, E.B. 2003. Nuclear translation: What is the evidence? RNA 9: 1-8.

Dostie, J., Ferraiuolo, M., Pause, A., Adam, S.A., and Sonenberg, N. 2000. A novel shuttling protein, $4 \mathrm{E}-\mathrm{T}$, mediates the nuclear import of the mRNA 5' cap-binding protein, eIF4E. EMBO J. 19: 31423156.

Elbashir, S.M., Harborth, J., Lendeckel, W., Yalcin, A., Weber, K., and Tuschl, T. 2001. Duplexes of 21-nucleotide RNAs mediate RNA interference in cultured mammalian cells. Nature 411: 494-498.

Frischmeyer, P.A. and Dietz, H.C. 1999. Nonsense-mediated mRNA decay in health and disease. Hum. Mol. Genet. 8: 1893-1900.

Gehring, N.H., Neu-Yilik, G., Schell, T., Hentze, M.W., and Kulozik, A.E. 2003. Y14 and hUpf3b form an NMD-activating complex. Mol. Cell 11: 939-949.

Gersappe, A. and Pintel, D.J. 1999. A premature termination codon interferes with the nuclear function of an exon splicing enhancer in an open reading frame-dependent manner. Mol. Cell. Biol. 19: $1640-1650$.

Hentze, M.W. and Kulozik, A.E. 1999. A perfect message: RNA surveillance and nonsense-mediated decay. Cell 96: 307-310.

Hilleren, P. and Parker, R. 1999. Mechanisms of mRNA surveillance in eukaryotes. Annu. Rev. Genet. 33: 229-260.

Iborra, F.J., Jackson, D.A., and Cook, P.R. 2001. Coupled transcription and translation within nuclei of mammalian cells. Science 293: 1139-1142.

Ishigaki, Y., Li, X., Serin, G., and Maquat, L.E. 2001. Evidence for a pioneer round of mRNA translation: mRNAs subject to nonsensemediated decay in mammalian cells are bound by CBP80 and CBP20. Cell 106: 607-617.

Jacobson, A. and Peltz, S.W. 1996. Interrelationships of the pathways of mRNA decay and translation in eukaryotic cells. Annu. Rev. Biochem. 65: 693-739.

Kim, V.N., Kataoka, N., and Dreyfuss, G. 2001. Role of the nonsensemediated decay factor hUpf3 in the splicing-dependent exon-exon junction complex. Science 293: 1832-1836.

Kingston, R.E. 1992. Introduction of DNA into mammalian cells. In Short protocols in molecular biology (eds. F.M. Ausubel et al.), pp. 9.1-9.16. J. Wiley, New York.

Le Hir, H., Gatfield, D., Izaurralde, E., and Moore, M.J. 2001. The exon-exon junction complex provides a binding platform for factors involved in mRNA export and nonsense-mediated mRNA decay. EMBO J. 20: 4987-4997.

Li, S. and Wilkinson, M.F. 1998. Nonsense surveillance in lymphocytes? Immunity 8: 135-141.

Li, S., Leonard, D., and Wilkinson, M.F. 1997. T cell receptor (TCR) mini-gene mRNA expression regulated by nonsense codons: A nuclear-associated translation-like mechanism. J. Exp. Med. 185: 985-992.

Li, B., Wachtel, C., Miriami, E., Yahalom, G., Friedlander, G., Sharon, G., Sperling, R., and Sperling, J. 2002. Stop codons affect 5' splice site selection by surveillance of splicing. Proc. Natl. Acad. Sci. 99: 5277-5282.

Lund, E. and Dahlberg, J.E. 1998. Proofreading and aminoacylation of tRNAs before export from the nucleus. Science 282: 2082-2085.

Lykke-Andersen, J., Shu, M.D., and Steitz, J.A. 2000. Human Upf proteins target an mRNA for nonsense-mediated decay when bound downstream of a termination codon. Cell 103: 1121-1131. - 2001. Communication of the position of exon-exon junctions to the mRNA surveillance machinery by the protein RNPS1. Science 293: 1836-1839.

Maquat, L.E. 1995. When cells stop making sense: Effects of nonsense codons on RNA metabolism in vertebrate cells. RNA 1: 453-465.

- 2002. NASty effects on fibrillin pre-mRNA splicing: Another case of ESE does it, but proposals for translation-dependent splice site choice live on. Genes \& Dev. 16: 1743-1753.

Medalia, O., Typke, D., Hegerl, R., Angenitzki, M., Sperling, J., and Sperling, R. 2002. Cryoelectron microscopy and cryoelectron tomography of the nuclear pre-mRNA processing machine. J. Struct. Biol. 138: 74-84.

Mendell, J.T., Medghalchi, S.M., Lake, R.G., Noensie, E.N., and Dietz, H.C. 2000. Novel Upf2p orthologues suggest a functional link between translation initiation and nonsense surveillance complexes. Mol. Cell. Biol. 20: 8944-8957.

Mendell, J.T., ap Rhys, C.M.J., and Dietz, H.C. 2002. Separable roles for rent1/hUpf1 in altered splicing and decay of nonsense transcripts. Science 298: 419-422.

Miriami, E., Sperling, J., and Sperling, R. 1994. Heat shock affects 5' 


\section{Wachtel et al.}

splice site selection, cleavage and ligation of CAD pre-mRNA in hamster cells, but not its packaging in lnRNP particles. Nucleic Acids Res. 22: 3084-3091.

Miriami, E., Motro, U., Sperling, J., and Sperling, R. 2002. Conservation of an open-reading frame as an element affecting $5^{\prime}$ splice site selection. J. Struct. Biol. 140: 116-122.

Miriami, E., Sperling, R., Sperling, J., and Motro, U. 2004. Regulation of splicing: The importance of being translatable. RNA 10: $1-4$.

Mühlemann, O., Mock-Casagrande, C.S., Wang, J., Li, S., Custodio, N., Carmo-Fonseca, M., Wilkinson, M.F., and Moore, M.J. 2001. Precursor RNAs harboring nonsense codons accumulate near the site of transcription. Mol. Cell 8: 33-44.

Müller, S., Wolpensinger, B., Angenitzki, M., Engel, A., Sperling, J., and Sperling, R. 1998. A supraspliceosome model for large nuclear ribonucleoprotein particles based on mass determinations by scanning transmission electron microscopy. J. Mol. Biol. 283: 383-394.

Nathanson, L., Xia, T., and Deutscher, M.P. 2003. Nuclear protein synthesis: A re-evaluation. RNA 9: 9-13.

Neufeld, E.F. 1991. Lysosomal storage diseases. Ann. Rev. Biochem. 60: $257-280$.

Nilsen, T.W. 1998. RNA-RNA interactions in nuclear pre-mRNA splicing. In RNA structure and function (eds. R.W. Simons and M. Grunberg-Manago), pp. 279-307. Cold Spring Harbor Laboratory Press, Cold Spring Harbor, NY.

Ohnishi, T., Yamashita, A., Kashima, I., Schell, T., Anders, K.R., Grimson, A., Hachiya, T., Hentze, M.W., Anderson, P., and Ohno, S.
2003. Phosphorylation of hUPF1 induces formation of mRNA surveillance complexes containing hSMG-5 and hSMG-7. Mol. Cell 12: $1187-1200$.

Padgett, R.A., Wahl, G.M., and Stark, G.R. 1982. Structure of the gene for CAD, the multifunctional protein that initiates UMP synthesis in Syrian hamster cells. Mol. Cell. Biol. 2: 293-301.

Rajavel, K.S. and Neufeld, E.F. 2001. Nonsense-mediated decay of human HEXA mRNA. Mol. Cell. Biol. 21: 5512-5519.

Staley, J.P. and Guthrie, C. 1998. Mechanical devices of the spliceosome: Motors, clocks, springs, and things. Cell 92: 315-326.

Sun, X., Perlick, H.A., Dietz, H.C., and Maquat, L.E. 1998. A mutated human homologue to yeast Upf1 protein has a dominant-negative effect on the decay of nonsense-containing mRNAs in mammalian cells. Proc. Natl. Acad. Sci. 95: 10009-10014.

Valentine, C.R. 1998. The association of nonsense codons with exon skipping. Mutat. Res. 411: 87-117.

Wang, J., Hamilton, J.I., Carter, M.S., Li, S., and Wilkinson, M.F. 2002a. Alternatively spliced TCR mRNA induced by disruption of reading frame. Science 297: 108-110.

Wang, J., Vock, V.M., Li, S., Olivas, O.R., and Wilkinson, M.F. 2002 b. A quality control pathway that down-regulates aberrant T-cell receptor (TCR) transcripts by a mechanism requiring UPF2 and translation. J. Biol. Chem. 277: 18489-18493.

Zhang, J., Sun, X., Qian, Y., and Maquat, L.E. 1998. Intron function in the nonsense-mediated decay of $\beta$-globin mRNA: Indications that pre-mRNA splicing in the nucleus can influence mRNA translation in the cytoplasm. RNA 4: 801-815. 

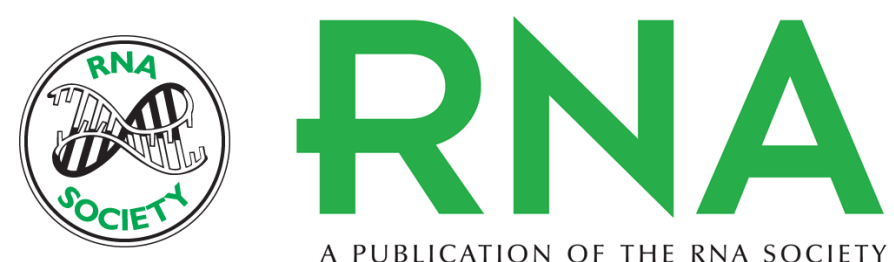

A PUBLICATION OF THE RNA SOCIETY

\section{Stop codon-mediated suppression of splicing is a novel nuclear scanning mechanism not affected by elements of protein synthesis and NMD}

CHAIM WACHTEL, BINGHUI LI, JOSEPH SPERLING, et al.

RNA 2004 10: 1740-1750

References This article cites 46 articles, 24 of which can be accessed free at:

http://rnajournal.cshlp.org/content/10/11/1740.full.html\#ref-list-1

License

Email Alerting Receive free email alerts when new articles cite this article - sign up in the box at the

Service top right corner of the article or click here.

To subscribe to $R N A$ go to:

http://rnajournal.cshlp.org/subscriptions 